\title{
A comparative study of adverse factors in meningococcaemia and meningococcal meningitis
}

\author{
B. M. ANSARI \\ M.R.C.P., D.C.H.
}

D. B. Davies

M.R.C.P., D.C.H.

\section{Summary}

In a retrospective study, a comparison was made of clinical and laboratory data in 14 patients with meningococcaemia and 40 patients with meningococcal meningitis. Significant differences were found in duration of symptoms, onset of purpura, presence of shock, initial WBC, ESR, and serum fibrin degradation products. The overall mortality rate in this series was $7 \%, 4$ patients with meningococcaemia dying, but none with meningococcal meningitis. This study indicates the importance of clinical and pathological grading of patients with meningococcaemia. Death occurred only in patients presenting with 3 or more of the adverse factors detailed.

\section{Introduction}

A high mortality is a recognized feature of meningococcaemia, contrasting sharply with meningococcal meningitis where the prognosis is more favourable (Stiehm and Damrosch, 1966; Hunter, 1973). The manifestations of meningococcaemia are usually characterized by rapid onset of symptoms, purpura, severe shock and disseminated intravascular coagulation (DIC). These developments have been described in the literature by various authors and the mechanisms considered were adrenal insufficiency (Cosgriff, 1944), endotoxic shock (May, 1960), and generalized Shwartzman reactions (Sternberg et al., 1951; Margaretten and McAdams, 1958). The pathological changes seen in fatal cases with DIC were reported by Margaretten, Csavossy and McKay (1967), Evans et al. (1969) and Fox (1971). Laboratory evidence documented by McGehee, Rapaport and Hjort (1967) suggested a direct relationship between this complication and a poor prognosis. With this background, the present authors reviewed 14 cases of meningococcaemia and compared them with 40 of meningococcal meningitis with a view to evaluating first, the clinical and laboratory data and second, the adverse factors occurring in these diseases. By doing this, the authors believe that patients at risk may be more quickly recognized and therapy started early in patients with fulminant disease.

\section{Patients and methods}

The case records of 54 children with meningococcaemia and meningococcal meningitis admitte to East Glamorgan General Hospital were reviewe retrospectively in the 5 years 1972 to 1976 . Meninge $\overrightarrow{0}$ coccaemia was diagnosed in those patients wit blood cultures positive for Neisseria meningitidis but whose CSFs showed normal cytology and biochemistry as well as absence of organisms seen or cultured (13 cases). One case of meningococcaemia was presumed in a patient with local skin lesion culture positive for $N$. meningitidis although blood culture was negative. Meningococcal meningitis was considered present when more than $10 \mathrm{WBC} / \mathrm{mm}^{3}$ were found in the CSF and accompanied by either positive cultures of $N$. meningitidis in the CSF (36 cases) or negative cultures but where Gram-negative intracellular diplococci morphologically identical to $N$. meningitidis were found in the smears taken from the CSF ( 4 cases). In the latter category all 4 patients had a typical clinical course with purpura suggesting meningococcal infection.

Analysis of the case records was made for the clinical status of the patients. This included age, sex, duration of symptoms $(<$ or $>24 \mathrm{hr}$ ), onset of purpura $(<$ or $>12 \mathrm{hr}$ ), temperature on admission $\sigma$ $\left(<\right.$ or $\left.>39^{\circ} \mathrm{C}\right)$, presence or absence of shock, $N$ presence or absence of convulsions, anticoagulation $\mathrm{N}$ therapy and final outcome. The laboratory data 0 analysed were the initial WBC $(<$ or $>15 \times$

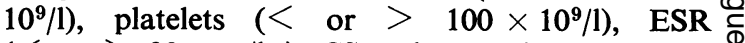
( $<$ or $>20 \mathrm{~mm} / \mathrm{hr}$ ), CSF pleocytosis, and serum $\stackrel{\oplus}{\rightarrow}$ fibrin degradation products (FDPs) $(<$ or $>407$ 
$\mu \mathrm{g} / \mathrm{ml})$. Data relating to serotyping of strains of $N$. meningitidis were available for analysis in 25 patients. Sulphonamide sensitivity of strains was determined in 48 patients using sulphadiazine $100 \mu \mathrm{g}$ discs tested on para-aminobenzoic acid-free medium $(10 \%$ chocolate diagnostic sensitivity agar (Oxoid)).

All patients received standard antibiotic treatment with penicillin or ampicillin in appropriate doses with or without sulphonamides. Thirteen patients also received chloramphenicol initially for $48 \mathrm{hr}$. $\chi^{2}$ contingency tables and the Wilcoxon Rank Test were used in the statistical analysis.

\section{Results}

\section{Clinical data}

Age was not a significantly different factor between the meningococcaemia and meningococcal meningitis patients. The male : female ratio between 2 groups was $1 \cdot 8: 1$ and $2 \cdot 1: 1$ respectively. 'Twelve out of 14 patients with meningococcaemia $(85.7 \%)$ became ill within $24 \mathrm{hr}$ and their onset of purpura was significantly more rapid $(<12 \mathrm{hr})$ than in those with meningococcal meningitis $(P<0.01)$. Shock was also significantly more common in this group but convulsions and temperature were not (Table 1).

\section{Laboratory data}

Eleven out of 12 patients with meningococcaemia had WBC $<15 \times 10^{9} / 1$ compared with 18 out of 40 with meningococcal meningitis $(P<0.05)$. Highly significant differences between the groups were obtained with regard to low ESR $(<20 \mathrm{~mm} / \mathrm{hr})$ and high serum FDPs $(>40 \mu \mathrm{g} / \mathrm{ml})$. The presence of thrombocytopenia was not significantly different (Table 2).

\section{Serotyping and sulphonamide sensitivity}

Serotyping data were analysed in 8 patients with meningococcaemia and 17 patients with meningococcal meningitis. In meningococcaemia, 4 strains of $N$. meningitidis were Group A and 4 were Group B. In meningococcal meningitis there were 9 strains of Group A, 6 of Group B, one of Group C and one which was not A, B, C or D. Serotyping data were available in only 2 of the 4 patients who died with meningococcaemia. One strain was Group A and the other Group B.

Of the meningococci isolated from patients with meningococcaemia all were fully sensitive to sulphadiazine. However, 9 of the $36(25 \%)$ meningococci isolated from children with meningococcal meningitis were resistant to sulphonamide.

\section{Adverse factors affecting prognosis}

The patients in the 2 groups were given a prognostic score on the basis of significant clinical and laboratory data (Table 3). These were analysed separately because all 4 laboratory parameters were complete in 24 patients only (Table 4). In patients who had a clinical and laboratory score of 3 or 4 adverse factors the mortality rate was 66 and $20 \%$ respectively. The latter might have been higher if complete laboratory data had been available for the other 3 patients who died (Table 5).

Patients 1 and 3 died soon after admission and all 4 children died within $19 \mathrm{hr}$ of admission. Heparin was used in patients 2 and 4 but was also given to 3

TABLE 1. Showing clinical data of patients with meningococcaemia and meningococcal meningitis

\begin{tabular}{|c|c|c|c|c|c|c|c|c|c|}
\hline & $\begin{array}{c}\text { Mean } \\
\text { age } \\
\text { (months) }\end{array}$ & $\begin{array}{l}\text { Sex } \\
\text { M/F }\end{array}$ & $\begin{array}{c}\text { Anticoag- } \\
\text { ulation } \\
\text { (heparin) }\end{array}$ & $\begin{array}{c}\text { Duration of } \\
\text { symptoms } \\
(<24 \mathrm{hr})\end{array}$ & $\begin{array}{c}\text { Onset of } \\
\text { purpura } \\
(<12 \mathrm{hr})\end{array}$ & Shock & $\begin{array}{l}\text { Convul- } \\
\text { sions }\end{array}$ & $\begin{array}{l}\text { Temp. } \\
>39^{\circ} \mathrm{C}\end{array}$ & Mortality \\
\hline $\begin{array}{l}\text { Meningococcaemia } \\
(n=14) \text { except } \\
\text { Meningococcal }\end{array}$ & $20 \cdot 6$ & $1 \cdot 8: 1$ & 5 & $12(85.7 \%)$ & $12(85 \cdot 7 \%)$ & $6(42 \cdot 8 \%)$ & $4(28.6 \%)$ & $\begin{array}{c}7(58 \cdot 3 \%) \\
*\end{array}$ & $4(28.5 \%)$ \\
\hline $\begin{array}{l}\text { meningitis } \\
(n=40)\end{array}$ & 33.9 & $2: 1$ & 0 & $5(12.5 \%)$ & $10(25 \%)$ & $1(2 \cdot 5 \%)$ & $5(12 \cdot 5 \%)$ & $9(22.5 \%)$ & 0 \\
\hline Significance & ns & ns & & $P<0.01$ & $P<0.01$ & $P<0.01$ & ns & ns & $P<0.003$ \\
\hline
\end{tabular}

*(n=12).

TABLE 2. Laboratory data of patients with meningococcaemia and meningococcal meningitis

\begin{tabular}{lcccc}
\hline & WBC & ESR & Platelets & FDPs \\
& $<15 \times 10 \% / 1$ & $<20 \mathrm{~mm} / \mathrm{hr}$ & $<100 \times 10 / 91$ & $>40 \mu \mathrm{g} / \mathrm{ml}$ \\
\hline Meningococcaemia & $11(91.6 \%)$ & $9(90 \%)$ & $4(33.3 \%)$ & $7(70 \%)$ \\
Meningococcal meningitis & $n=12$ & $n=10$ & $n=10$ & 0 \\
Significance & $18(45 \%)$ & $2(4.2 \%)$ & $2(7.4 \%)$ & $n=27$ \\
ns & $n=24$ & $P<0.005$ & 18 \\
\hline
\end{tabular}


other patients with meningococcaemia and DIC who survived. There were no fatalities in children with meningococcal meningitis and the majority of children had no adverse factors (Table 4). Fatality occurred only in patients with meningococcaemia and those with adverse factors of 3 and 4 on clinical and laboratory grading. Shock and raised serum FDPs (suggesting DIC) were possibly the 2 most important factors contributing to death. A high level of serum FDPs was found in patients with 3 or 4 adverse laboratory factors. DIC was probably present in 4 patients with meningococcaemia who were shocked, as these had raised serum FDPs. However, of the 7 patients with raised serum FDPs, 4 had thrombocytopenia but 3 had normal platelet count.

TABLE 3. Adverse factors affecting prognosis in meningococcaemia

Clinical

Symptoms lasting $<24 \mathrm{hr}$

Purpura lasting $<24 \mathrm{hr}$

Presence of shock

Laboratory

Absence of meningitis

Absence of leucocytosis

Low ESR

Presence of disseminated intravascular coagulation

\section{Post-mortem data}

Post-mortem was performed in 2 cases only. The CNS showed congestion in some blood vessels, but no acute inflammation of the brain or meninges was seen.

\section{Discussion}

This study has shown that meningococcaemia remains a potentially fulminating disease with a mortality rate which is unacceptably high.

In this series of meningococcal disease the overall fatality rate was $7 \%$ occurring with an accumulation of adverse factors. It is possible at the onset to distinguish meningococcaemia from meningococcal meningitis on the basis of clinical and laboratory findings. Stiehm and Damrosch (1966) mentioned 5 adverse prognostic factors: these were rapid onset of purpura, presence of shock, low ESR and absence of meningitis and leucocytosis. The present authors have analysed a number of clinical and laboratory variables and on the basis of significant statistical tests added 2 more factors, namely short duration of symptoms $(<24 \mathrm{hr})$ and presence of DIC. The authors feel that the addition of these 2 factors are necessary as some patients may not have purpura or develop this after admission, and also because there is a direct relationship between shock and DIC in meningococcaemia. However, they accept that a raised serum FDP is not essential for the diagnosis of DIC, although this is suggestive evidence of this condition.

Although serotyping results of meningoccoci isolated were available in only a few cases, there did not appear to be any correlation between serotype of strain and severity of illness in this series and would appear that adverse effects were probabls produced by an inadequate host response.

There was no mortality from meningococcaf meningitis as there were fewer patients with adverse factors and none with 3 factors overall. The authors feel that the identification of the child at risk should be done immediately when meningococcal disease is evident and appropriate measures taken to combat shock and DIC. Heparin therapy was instituted

TABLE 4. Mortality and relationship to clinical and laboratory scoring

\begin{tabular}{lcccccccccccc}
\hline & \multicolumn{1}{c}{ Clinical scoring } & \multicolumn{3}{c}{ Laboratory scoring } \\
\hline & $n$ & 0 & 1 & 2 & 3 & $n$ & 0 & 1 & 2 & 3 & 4 \\
Meningococcaemia & 14 & 1 & 1 & 6 & 6 & 10 & 0 & 1 & 2 & 2 & 5 \\
Mortality & - & 0 & 0 & 0 & 4 & - & 0 & 0 & 0 & 0 & 1 \\
Meningococcal meningitis & 40 & 27 & 10 & 3 & 0 & 14 & 12 & 2 & 0 & 0 & 0 \\
\hline
\end{tabular}

TABLE 5. Clinical and laboratory data of 4 children who died with meningococcaemia

\begin{tabular}{|c|c|c|c|c|c|c|c|c|c|c|c|}
\hline Patients & $\begin{array}{c}\text { Age } \\
\text { (months) }\end{array}$ & Sex & $\underset{\text { (hr) }}{\text { Symptoms }}$ & $\begin{array}{l}\text { Onset of } \\
\text { purpura } \\
\text { (hr) }\end{array}$ & $\begin{array}{l}\text { Shock } \\
+1-\end{array}$ & $\begin{array}{l}\text { WBC } \\
\times 10^{9} / 1\end{array}$ & $\begin{array}{l}\text { ESR } \\
\mathrm{mm} / \mathrm{hr}\end{array}$ & $\begin{array}{c}\text { Platelets } \\
\times 10^{9} / 1\end{array}$ & $\begin{array}{c}\mathrm{SCF} \\
\mathrm{WCB} / \mathrm{mm}^{3}\end{array}$ & FDPs & $\begin{array}{c}\text { Time interval } \\
\text { between admission } \\
\text { and death }\end{array}$ \\
\hline 1 & 60 & $\mathbf{M}$ & 8 & 1 & + & ND & ND & ND & 0 & ND & $15 \mathrm{~min}$ \\
\hline 2 & 11 & F & 18 & 14 & + & 4 & ND & $52 \times 10^{3}$ & 0 & $>40 \mu \mathrm{g} / \mathrm{ml}$ & $6 \mathrm{hr}$ \\
\hline 3 & 7 & $\mathrm{~F}$ & 12 & 4 & + & ND & ND & ND & 0 & ND & $60 \mathrm{~min}$ \\
\hline 4 & 15 & $\mathbf{M}$ & 6 & $\begin{array}{c}\text { After } \\
\text { admission }\end{array}$ & + & $3 \cdot 1$ & 3 & $86 \times 10^{3}$ & 0 & $>40 \mu \mathrm{g} / \mathrm{ml}$ & $19 \mathrm{hr}$ \\
\hline
\end{tabular}

$\mathrm{ND}=$ not done 
early in 5 patients with DIC and although 2 children died, 3 were probably saved by this treatment.

In 3 patients with meningococcaemia the level of serum FDPs was not elevated. These children recovered and were not given anticoagulants. It is possible that these patients could have developed meningitis given time, but there is no evidence to support this hypothesis. There are experimental data to suggest that early treatment with heparin is effective in controlling DIC (Filkins and Di Luzio, 1968). However, when this therapy is given after the onset of shock it does not improve survival (Corrigan and Jordan, 1970). Blum et al. (1973) showed that mortality rate in meningococcaemia fell from $19 \%$ ( 5 of 26 cases) to $3.7 \%$ ( 2 of 53 cases) following early anticoagulation for shock and DIC. Owing to the lack of controlled studies, there is no definite proof of the efficacy of heparin against this condition.

\section{Acknowledgments}

We would like to thank our colleague, Dr W. Davies, Consultant Paediatrician for allowing us to review his patients, Mrs J. P. Jenkins and Mrs M. Rogers for secretarial help and Mr M. Campbell, M.R.C. Pneumoconiosis Unit, Llandough Hospital, Penarth, for statistical help.

\section{References}

Blum, D., Fondu, P., Denolin-Reubens, R. \& Dubois, J. (1973) Early heparin therapy in 60 children with acute meningococcaemia. Relationship between clinical manifestation and coagulation abnormalities. Acta chirurgica belgica, 72, 288.
Corrigan, J.J. \& Jordan, C.M. (1970) Heparin therapy in septicemia with disseminated intravascular coagulation, New England Journal of Medicine, 283, 778.

CosGriff, S.W. (1944) The Waterhouse-Friderichsen syndrome. Observation associated adrenal insufficiency and report of 4 cases. Annals of Internal Medicine, 21, 187.

Evans, R.W., Glick, B., Kimball, F. \& Lobell, M. (1969) Fatal intravascular consumption coagulopathy in meningococcal sepsis. American Journal of Medicine, 46, 910.

FILKINS, J.P. \& Di LuzIo, N.R. (1968) Heparin protection in endotoxin shock. American Journal of Physiology, 214, 1074.

Fox, B. (1971) Disseminated intravascular coagulation and Waterhouse-Friderichsen syndrome. Archives of Disease in Childhood, 46, 680.

HunTER, J. (1973) Heparin therapy in meningococcal septicaemia. Archives of Disease in Childhood. 48, 233.

McGehee, W.G., Rapaport, S.I. \& HJorT, P.F. (1967) Intravascular coagulation in fulminant meningococcemia. Annals of Internal Medicine, 67, 250.

Margaretten, W., Csavossy, I. \& MCKay, D.G. (1967) An electron microscope study of a case of meningococcemia in man. American Journal of Diseases of Children, 114, 268.

Margaretten, W. \& McAdams, A.J. (1958) An appraisal of fulminant meningococcemia with reference to the Shwartzman phenomenon. American Journal of Medicine, 25, 868.

MAY, C.D. (1960) Circulatory failure (shock) in fulminant meningococcal infection; an enquiry into the pathogenesis as an approach to rational therapy. Pediatrics, 25, 316.

SternberG, S.D., ZWeiffler, B.M., Gruber, S. \& Lichterman, J. (1951) The Shwartzman phenomenon complicating acute meningococcemia with meningitis. Journal of Pediatrics, 38, 369.

Stiehm, E.R. \& Damrosch, D.S. (1966) Factors in the prognosis of meningococcal infection. Journal of Pediatrics, $68,457$. 